\title{
Téoros
}

Revue de recherche en tourisme

\section{Les Français au Québec} Un marché d'avenir?

\section{Jean Stafford et Bruno Sarrasin}

Volume 16, numéro 3, automne 1997

URI : https://id.erudit.org/iderudit/1073322ar

DOI : https://doi.org/10.7202/1073322ar

Aller au sommaire du numéro

Éditeur(s)

Université du Québec à Montréal

ISSN

0712-8657 (imprimé)

1923-2705 (numérique)

Découvrir la revue

\section{Citer cette note}

Stafford, J. \& Sarrasin, B. (1997). Les Français au Québec : un marché d’avenir ?

Téoros, 16(3), 46-48. https://doi.org/10.7202/1073322ar d'utilisation que vous pouvez consulter en ligne.

https://apropos.erudit.org/fr/usagers/politique-dutilisation/ 


\section{Les Français au Québec UN MARCHÉ D'AVENIR?}

Jean Stafford, professeur

Département d'études urbaines et touristiques - UQAM

Bruno Sarrasin, chargé de cours

Département d'études urbaines et touristiques - UQAM

Cette chronique porte sur la conjoncture touristique. Elle propose un portrait simplifié de la situation du tourisme à partir d'une clientele précise et des données disponibles. Les notions usuelles de l'analyse prévisionnelle seront utilisées: la tendance (passée, présente et future), la saisonnalité, le cycle et les mouvements irréguliers. Les prévisions seront faites pour les cinq prochaines années.

Les touristes français représentent la clientèle étrangère la plus importante au Québec, loin cependant derrière les Américains. L'engouement des Français pour le Québec s'est décuplé depuis le début de la décennie, passant de $7,7 \%$ du tourisme international en 1990 à $12 \%$ en 1995. Cette augmentation de plus de $55 \%$ en cinq ans peut difficilement passer inaperçue, Est-elle le résultat de quelque conjoncture des années 1990 ou témoigne-t-elle de la continuité d'une tendance bien établie depuis les années 1970 ? Ce court article tentera d'apporter quelques précisions, et dégagera quelques enjeux pour l'avenir.

\section{TENDANCES}

L'arrivée des touristes français au Québec affiche une croissance annuelle moyenne de $9 \%$ depuis les 20 dernières années (tableau 1). En hausse moyenne durant toute cette période, le comportement de cette clientèle prend l'allure d'un cycle. En forte augmentation entre 1977 et $1981(12,6 \%)$, on assiste à une réduction de $75 \%$ de la croissance moyenne au cours des cinq annees suivantes. 1987 aे
1991 présentent les cinq meilleures années de la période avec un taux d'accroissement annuel moyen de $14 \%$, suivi d'une diminution de moitié de la croissance entre 1992 et 1996.

A ce titre, deux types d'explications méritent d'être soulignés. Le premier est économique; sur une période de 20 ans, malgré une crise du pétrole et deux récessions majeures, les Français, année après année, sont venus visiter le Québec tou- jours en plus grand nombre (sauf en 1983, 1985 et 1992). La seconde explication est d'ordre conjoncturel; un taux de change généralement favorable au cours des dix dernières années, le dollar canadien suivant une politique de monnaie faible par rapport au dollar américain. Le franc, particulièrement avec les critères de convergence de la monnaie unique européenne des années 1990, s'est généralement fixé au mark, en monnaie forte. Ces conditions ont pour effet de réduire le coût des produits et services payés en francs au Québec. La différence entre le prix des produits français et ceux vendus au Québec est telle que certains voyagistes ont trouvé avantageux d'offrir au Français un forfait week-end de magasinage au Québec". Il est cependant clair que l'essentiel de la clientèle française voyageant au Québec ne le fait pas seulement pour un week-end!

Malgré le fractionnement et la réduction du temps de vacances observé dans la plupart des pays industrialisés depuis le

\section{TABLEAU 1}

L'arrivée des touristes français au Québec; les taux d'accroissement annuels moyens (moyenne géométrique), de 1977 à 1996 par périodes de cinq années

\begin{tabular}{|c|c|}
\hline Années & $\begin{array}{c}\text { Taux d'accroissement } \\
\text { en \% }\end{array}$ \\
\hline $1977-1981$ & 12,6 \\
\hline $1982-1986$ & 3,2 \\
\hline $1987-1991$ & 14,0 \\
\hline $1992-1996$ & 7,0 \\
\hline $1977-1996$ & 9,0 \\
\hline
\end{tabular}

Sourco: nos calculs à partir des donnëes de Statistique Canada. 
début des années 1990, les Français représentaient la clientèle ćtrangère au Québec dont la durée de séjour était la plus longue en 1994 (Tourisme Québec, 1995). Cette durée correspond à trois fois celle des Américains ( 10,1 nuitées contre 3,5) et va jusqu'à 12,8 nuitées lorsque la motivation du voyage est la visite de parents et amis. S'ils représentent un peu plus de $10 \%$ du tourisme international au Québec, les Français apportent $20 \%$ du total des dépenses faites au Québec par les touristes étrangers. En 1994, nos cousins dépensaient $824 \$$ en moyenne par séjour, soit deux fois plus que le total dépensé en moyenne au Québec par chaque Américain. Le ratio dépenses/nuitée révèle cependant que les Français dépensent près de $30 \%$ de moins par nuitée que nos voisins. En d"autres termes, si les Français séjournent plus longtemps, ils dépensent moins que les Américains par nuitée.

Intéresser les Américains à séjourner plus longtemps au Québec ou inciter les Français à dépenser plus, voilà qui contribuerait à tirer davantage profit de clientèles qui sont déja importantes pour le Québec, la première par son volume et l'autre par son taux de croissance et son potentiel à long terme. Mais lorsqu on parle de touristes français, à qui fait-on généralement référence? A deux adultes sans enfants (72,8\% en 1994), majoritairement âgés entre 25 et 54 ans $(51 \%$ de la clientèle d'agrément) et dont la motivation de voyage est l'agrément ${ }^{2}$ (Tourisme Québec, 1995). Le tourisme d'affaires quant a lui a littéralement diminué de moitié au cours des quatre premières années de la décennie, passant de $17,6 \%$ à $9,1 \%$. Est-ce à dire que le tourisme d'affaires est aux Américains ce que le tourisme d'agrément est aux Français? Cette équation permet d'insister sur les segments en croissance, en prenant soin de ne pas oublier que la grande majorité des Américains visite aussi le Québec par agrément.

\section{SAISONNALITÉ}

La saisonnalité de la clientèle française présente de fortes variations au cours des 20 dernières années. Principalement concentrée l'été (juin à septembre), les arrivées de Français ont varié de façon importante pour chaque mois de l'année, sauf pour janvier, mars, avril et octobre (tableau 2). Le mois de septembre présente sans

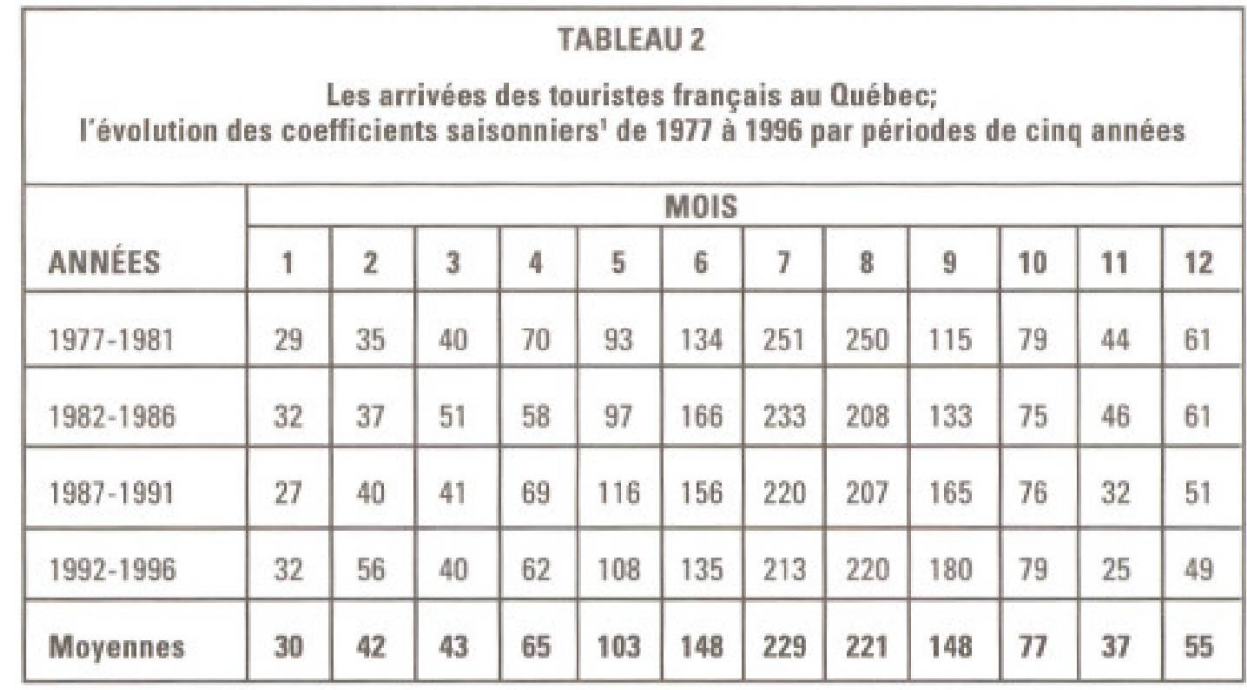

1 Ces cóefficients sont calculés a partir de la méthode de adécomposition dés séries chronologiquese a l'aide du logiciel SPSS, en utilisant les données de Statistique Canada.

\section{TABLEAU 3}

Les arrivées des touristes français au Québec, de 1977 à 1996; synthèse des éléments de décomposition de la série chronologique

\begin{tabular}{|ll|}
\hline Tendance: & Assez forte pour l'ensemble de la période considérée; $9 \%$ \\
\hline Saisonnalité: & $\begin{array}{l}\text { Très fortes variations; les coefficients saisonniers évoluent } \\
\text { entre } 29 \text { et } 229 \text { selon less mois et les années* }\end{array}$ \\
\hline Cycle: & $\begin{array}{l}\text { Très accentué; le coefficient de variation du cycle } \\
\text { est de } 54.7 \%\end{array}$ \\
\hline Mouvements irréguliers: & Assez forts; ces mouvements oscillent entre $\pm 11 \%$ \\
\hline
\end{tabular}

* Voir le tableau 2.

conteste la croissance la plus marquée sur une période de 20 ans, avec $+65 \%$. En fait, la période d'été semble avoir fait l'objet de plusieurs «réaménagementso depuis la fin des années 1970 . Le mois de juin a profité d'une hausse de $30 \%$ au cours des années 1980 , avant de revenir à son niveau initial. L'achalandage en juillet et août a baissé respectivement de $-38 \%$ et $-30 \%$ sur une période de 20 ans, même s'ils présentent encore de loin le plus grand nombre d'arrivées de touristes français ạ Québec. Novembre et décembre ont subi une chute d'intérêt de $-19 \%$ et $-12 \%$ de 1977 1981 à 1992-1996.

Encore plus de Français à l'été 1998? Voilà un scénario plausible, compte tenu de la croissance générale des arrivées et de leur concentration entre mai et septembre. Exception faite du mois de février, qui a connu une croissance de $21 \%$ entre 1977 et 1996 mais demeure peu important comparé à la période d'été. Les voyagistes ne semblent pas avoir réussi à vendre le froid québécois aux. Français, qui préfèrent en- core les activités estivales et automnales à l'aventure arctique.

\section{UN MARCHÉ DYNAMIQUE}

La principale caractéristique de la clientèle française, analysée à partir de la série chronologique, est la mobilité. Cette mobilité apparaît clairement dans l'analyse des différents mouvements de la série temporelle (tableau 3). La tendance générale des arrivées est assez forte si on la compare aux autres clientèles touristiques du Québec. La saisonnalité connaît de très grandes variations selon les mois de l'année et selon les différentes périodes. Le cycle est puissant et correspond (cela reste à vérifier) à des transformations au sein même de la clientèle française. Enfin, les mouvements aléatoires vont drainer une partie de la tendance à la hausse ou à la baisse. Cette clientele forme done un marché bien en vie, qui bouge et qui connaîtra de nouvelles métamorphoses. 


\section{ARRIVÉES}

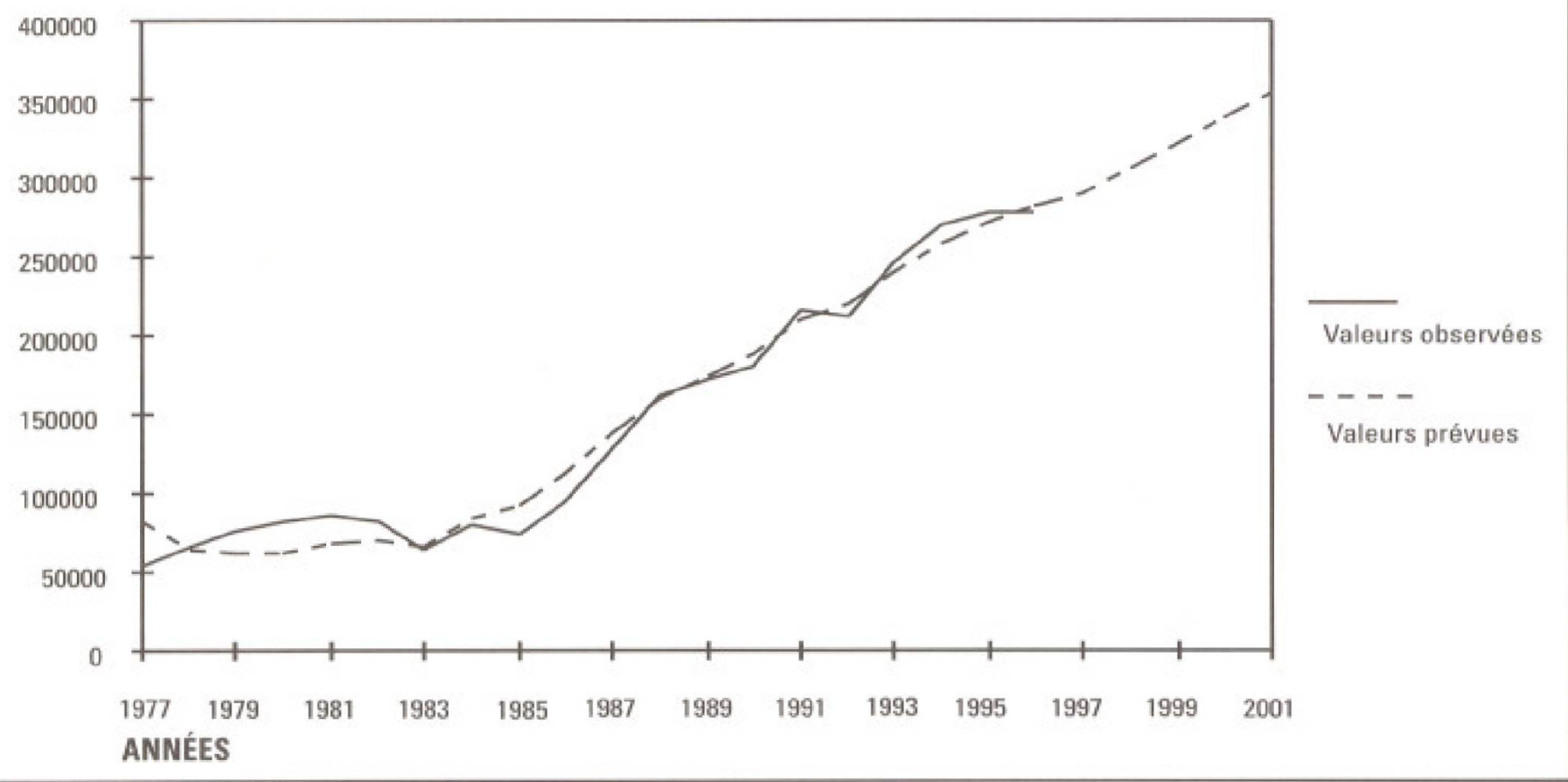

\section{QUEL AVENIR POUR} LE MARCHÉ FRANÇAIS?

Dans le passé, le marché français s'est comporté avec beaucoup d'irrégularités mais avec en toile de fond une croissance soutenue des arrivées, six fois plus nombreuses qu'il y a vingt ans. Loin d'être l'effet éphémère d'une mode, 1'intérêt qu'ont les Français pour le Québec semble s'être consolidé au cours des dernières années, offrant de longues périodes de fortes hausses ponctuées de courtes baisses, résistant même aux conjonctures économiques difficiles. Sans ajouter aux idées surfaites et aux stéréotypes, l'image du Québec véhiculée auprès des Français, autant sur le plan de la culture, des paysages que de l'accueil semble être efficace et porter fruits. Cela n"empêche pas d'innover, au contraire. Certains voyagistes se sont constitués des niches lucratives, contribuant ainsi à augmenter les dépenses des Français par sêjour. Mais voilà un segment bien mince de l'ensemble du marché. Si les Français visitent en moyenne un plus grand nombre de régions que nos voisins du sud lorsqu'ils sont au Québec, les visites de Manic 5 ou les expéditions de traîneaux à chiens représentent une infime fraction des activités de cette clientèle, la grande majorité voyageant en groupe, des chutes Niagara à Québec, en passant peut-être par la Gaspésie ou la région du Saguenay-LacSt-Jean.

Compte tenu de l'évolution de ce marché depuis les 20 dernières années et malgré l'introduction d'un cycle négatif pour les cinq prochaines années, de façon à refléter le ralentissement des arrivées observé depuis 1995, la lecture du graphique 1 montre une croissance annuelle moyenne de $5,1 \%$ entre 1997 et 2001 . Cette hypothèse minimale ne fait que confirmer la profondeur historique et la force du marché français. Cette croissance (de $5 \%$ environ) pourrait même se poursuivre jusqu'en 2006... Il devient donc urgent, à court terme, de faire des études plus poussées sur cette clientèle (ciblant notamment ses motivations et ses attentes) de façon à donner un peu de vigueur à une industrie québécoise atone et trop centrée sur le Canada et les États-Unis.

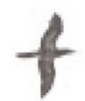

\section{NOTES}

1 Voir Claudine Hébert (1996), «Vendre l'hiver québécois au Françaisw, La Presse, samedi 9 novembre.

2 L'agrément comme motivation des woyageurs français est passée de $56 \%$ en 1990 à 67\% en 1994.

3 Voir Claudine Hébert, op. cit.

\section{BIBLIOGRAPHIE}

Commission canadienne du tourisme (1997), Programme de Marketing de l'Europe. Plan operationnel 1997/98, juillet.

Précourt, Diane (1996), «es 36 cordes sensibles des françaisi, Le Devoir, 4 juillet, p.I

The Canadian Tourism Commission (1996), European Travel Program, Ottawa.

Tourisme Québec (1995), La clientèle provenant de la France venue au Québec, Gouvernement du Québec, août.

Tourisme Québec (1995), Les touristes des pays autres que les Etats-Unis au Québec, Gouvernement du Québec, novembre.

Tourisme Québec (1997), Le tourisme au Québec en 1995. Une réalité économique importante, Gouvernement du Québec, mars. 